\title{
Effects of Concomitant Antiepileptic Drugs on Serum Carbamazepine Concentration in Epileptic Patients: Quantitative Analysis Based on Extracellular Water Volume as a Transforming Factor
}

\author{
Noriyasu FukUoKa, ${ }^{*, a}$ Toyohisa TsukAmoto, ${ }^{a}$ Junji UnO, ${ }^{b}$ \\ Michio KImURA, ${ }^{c}$ and Shushi MORITA ${ }^{a}$ \\ Department of Hospital Pharmacy, ${ }^{a}$ Kagawa Medical University, 1750-1 Ikenobe, Miki-cho, Kita-gun, \\ Kagawa 761-0793, Japan, Department of Hospital Pharmacy, ${ }^{b}$ Okehazama Hospital, 3-879 \\ Minamiyakata, Sakae-machi, Toyoake 470-1168, Japan, and Pharmaceutical Division, ${ }^{c}$ \\ Kurashiki Central Hospital, 1-1-1 Miwa, Kurashiki, Okayama 710-8602, Japan
}

(Received August 15, 2002; Accepted October 2, 2002)

\begin{abstract}
The effects of concomitant antiepileptic drugs on the serum carbamazepine concentration $\left(C_{\mathrm{t}}\right)$ were analyzed quantitatively. Primidone (PRM), phenobarbital (PB), phenytoin (PHT), valproic acid (VPA), zonisamide (ZNS), clonazepam (CZP), and ethosuximide (ETS) were coadministered with carbamazepine (CBZ). Routine therapeutic drug monitoring data, obtained from epileptic patients who were treated with the repetitive oral administration of CBZ fine granules/tablets, were used for the analysis. A total of 119 patients were administered CBZ alone, and 91, 39, 19, and 6 patients were coadministered one, two, three, and more than four different antiepileptic drugs, respectively. Using the data obtained from the patients administered CBZ alone, $C_{\mathrm{t}}$ could be expressed approximately as a function of the daily dose per extracellular water volume $\left(D / V_{\mathrm{ECW}}\right)$ as $C_{\mathrm{t}}=A\left(D / V_{\mathrm{ECW}}\right)^{\mathrm{B}}(A$, B: parameter $)$. By comparing the regression line on $\log C_{\mathrm{t}}$ vs. $\log \left(D / V_{\mathrm{ECW}}\right)$ for CBZ alone with that for CBZ plus another concomitant drug, $C_{\mathrm{t}}$ was thus found to be affected at each definite ratio by PB and PHT, but not by VPA and ZNS. We postulated a model showing that $C_{\mathrm{t}}$ is affected by each concomitant antiepileptic drug $i$ at each definite ratio. We defined the parameter $R_{\mathrm{i}}(i=1,2, \cdots, 7)$ representing the effect of each concomitant antiepileptic drug on $C_{\mathrm{t}}$. A linear polynomial expression, in which both members of this model are converted into common logarithms, was used for a multiple regression analysis. The analysis clarified that PB and PHT lowered $C_{\mathrm{t}}$ to 0.770 and 0.710 the value of CBZ alone, respectively. On the other hand, VPA and ZNS did not affect $C_{\mathrm{t}}$. The number of patients coadministered PRM, CZP, and/or ETS was not sufficient to detect the effect on $C_{\mathrm{t}}$ based on a test of significance. In the case of the addition or discontinuation of concomitant antiepileptic drugs in the same patient, the estimated $C_{\mathrm{t}}$ values were calculated using the value of each $R_{\mathrm{i}}$ and compared with the measured $C_{\mathrm{t}}$ values. Both values were in good agreement, and thus our results appear valid.
\end{abstract}

Key words_— carbamazepine; serum concentration; concomitant therapy; antiepileptic drug; alteration ratio

\section{INTRODUCTION}

Carbamazepine (CBZ) is widely used for the treatment of epilepsy. Many reports have referred to the changes in CBZ disposition caused by other concomitant antiepileptic drugs. ${ }^{1-3)}$ In those reports, when the serum CBZ concentration $\left(C_{\mathrm{t}}\right)$ was compared with the daily dose per body weight $(D / W), C_{\mathrm{t}}$ was affected by confounding factors such as age and sex. ${ }^{4,5)}$ A significant positive correlation was also observed between age and the level-dose (LD) ratio $C_{\mathrm{t}} /$ $(D / W) .6,7)$ The relationship between $C_{\mathrm{t}}$ and the daily dose has not been assessed directly. The regression line for $C_{\mathrm{t}}$ against $D / W$, which does not intersect the origin, was used for the analysis. Concerning the

e-mail: fukuoka@kms.ac.jp effects of concomitant antiepileptic drugs on $C_{\mathrm{t}}$, LD ratios were merely compared ${ }^{8,9)}$ and the effects were not evaluated quantitatively.

In our previous paper, ${ }^{10)}$ multiple regression analysis confirmed that $C_{\mathrm{t}}$ could only be correlated with the daily dose per extracellular water volume. In this study, we assumed that $C_{\mathrm{t}}$ was expressed as a power function of the daily dose per extracellular water volume and investigated which concomitant antiepileptic drugs affected $C_{\mathrm{t}}$ using a power function, in the same way as we investigated for valproic acid (VPA). ${ }^{11,12)}$ We showed the effects of concomitant antiepileptic drugs on $C_{\mathrm{t}}$ quantitatively, making it possible to estimate the changes in $C_{\mathrm{t}}$ values without grouping by other factors when the concomitant antiepileptic drugs are changed. 


\section{METHOD}

We collected data from epileptic patients who were chronically treated with repetitive oral administration of CBZ (Tegretol ${ }^{\circledR}$ granules/tablets, Novartis Pharma, Tokyo, Japan) at both Kagawa Medical University Hospital and Kurashiki Central Hospital from April 1996 to March 1997. Patients with abnormal findings on hepatic and renal function tests were excluded. All patients had been administered CBZ for more than 3 months. Blood samples were drawn 2 to $3 \mathrm{~h}$ after the last dosing in outpatients and 2 to $15 \mathrm{~h}$ after the last dosing in inpatients. When there were plural measurements for $C_{\mathrm{t}}$ in one patient with the same prescribed drugs during the study period, the mean value of $C_{\mathrm{t}}$ was used as the representative one. The age, body weight, height, and daily CBZ dose were also treated in the same manner. When there were several varieties of prescribed drugs in one patient, the count was taken as the number of patients. $C_{\mathrm{t}}$ was measured in duplicate using the FPIA method $\left(\right.$ TDX $^{\circledR}$ or FLX $^{\circledR}$ system, DAINABOT, Tokyo, Japan) and employed the mean value.

Data analysis was performed utilizing the statistical package NAP (ver.4). ${ }^{13)}$

\section{RESULTS}

1. Patient Characteristics Table 1 shows the characteristics of the patients administered CBZ in each hospital. Age and $C_{\mathrm{t}}$ were significantly different and the effect of both variables on the analysis are uncertain, but we assembled the data to elevate the potential of detection in the analysis.

2. Effects of Concomitant Antiepileptic Drugs on $C_{\mathrm{t}}$ (1) $\boldsymbol{C}_{\mathrm{t}}$ for $\mathbf{C B Z}$ Alone In the previous paper, ${ }^{10)}$ we investigated the most suitable transforming factor to relate the daily CBZ dose $(D)$ with the $C_{\mathrm{t}}$ for CBZ alone. Four types of transforming factor corresponding to clearance, i.e., body weight, total body water volume, body surface area, and extracellular water volume $\left(V_{\mathrm{ECW}}\right)$ were used. Multiple regression analysis confirmed that $C_{\mathrm{t}}$ was only dependent on $D / V_{\mathrm{ECW}}$. $V_{\mathrm{ECW}}$ was estimated by the following empirical formula ${ }^{14)}: V_{\mathrm{ECW}}[1]=0.068 \times$ body weight $[\mathrm{kg}]^{0.400} \times$ height $[\mathrm{cm}]^{0.633}$.

In Fig. 1, the plots show the relationship between $D$ $/ V_{\mathrm{ECW}}$ and $C_{\mathrm{t}}$ for $\mathrm{CBZ}$ alone. It appears that the increment in $C_{\mathrm{t}}$ decreases gradually with the increase in

Table 1. Patient Characteristics

\begin{tabular}{|c|c|c|c|c|}
\hline & \multicolumn{3}{|c|}{ Total or Mean \pm SD } & \multirow{2}{*}{$\mathrm{t}$ or $\chi^{2}$ test } \\
\hline & $\begin{array}{l}\text { Kagawa Medical } \\
\text { University Hospital }\end{array}$ & $\begin{array}{c}\text { Kurashiki Central } \\
\text { Hospital }\end{array}$ & Both hospitals & \\
\hline Total no. of patients & 99 & 175 & 274 & - \\
\hline \multirow{2}{*}{$\begin{array}{ll}\text { Sex: } S E X & \text { Male } \\
& \text { Female }\end{array}$} & 50 & 96 & 146 & \multirow{2}{*}{ NS } \\
\hline & 40 & 79 & 128 & \\
\hline Age: $A G E$ [years] & $26.2 \pm 18.9$ & $33.5 \pm 20.7$ & $\begin{array}{l}30.9 \pm 20.4 \\
\quad(1 \sim 82)\end{array}$ & $p<0.01$ \\
\hline Body weight: $W[\mathrm{~kg}]$ & $48.5 \pm 18.6$ & $51.0 \pm 15.9$ & $\begin{array}{c}50.1 \pm 16.9 \\
(11.0 \sim 96.0)\end{array}$ & NS \\
\hline Height: $H[\mathrm{~cm}]$ & $150.5 \pm 20.1$ & $153.8 \pm 21.4$ & $\begin{array}{l}152.6 \pm 21.0 \\
(80.0 \sim 182.5)\end{array}$ & NS \\
\hline Daily CBZ dose: $D[\mathrm{mg} /$ day $]$ & $462 \pm 198$ & $481 \pm 270$ & $\begin{array}{l}474 \pm 246 \\
(100 \sim 120)\end{array}$ & NS \\
\hline Serum CBZ concentration: $C_{\mathrm{t}}[\mu \mathrm{g} / \mathrm{ml}]$ & $7.00 \pm 2.51$ & $6.35 \pm 2.41$ & $\begin{array}{l}6.59 \pm 2.46 \\
(1.30 \sim 14.50)\end{array}$ & $p<0.05$ \\
\hline \multirow{2}{*}{$\begin{array}{l}\text { CBZ therapy Momo } \\
\text { Concomitant }\end{array}$} & 40 & 79 & 119 & \multirow{2}{*}{ NS } \\
\hline & 59 & 96 & 155 & \\
\hline No. of drugs & 40 & 51 & 91 & \multirow{4}{*}{$p<0.05$} \\
\hline \multirow[t]{3}{*}{ Coadministered } & 16 & 23 & 39 & \\
\hline & 1 & 18 & 19 & \\
\hline & 2 & 4 & 6 & \\
\hline
\end{tabular}

t, $\chi^{2}$ test: comparison between both hospitals. Values in parentheses indicate the range. NS: not significant. 


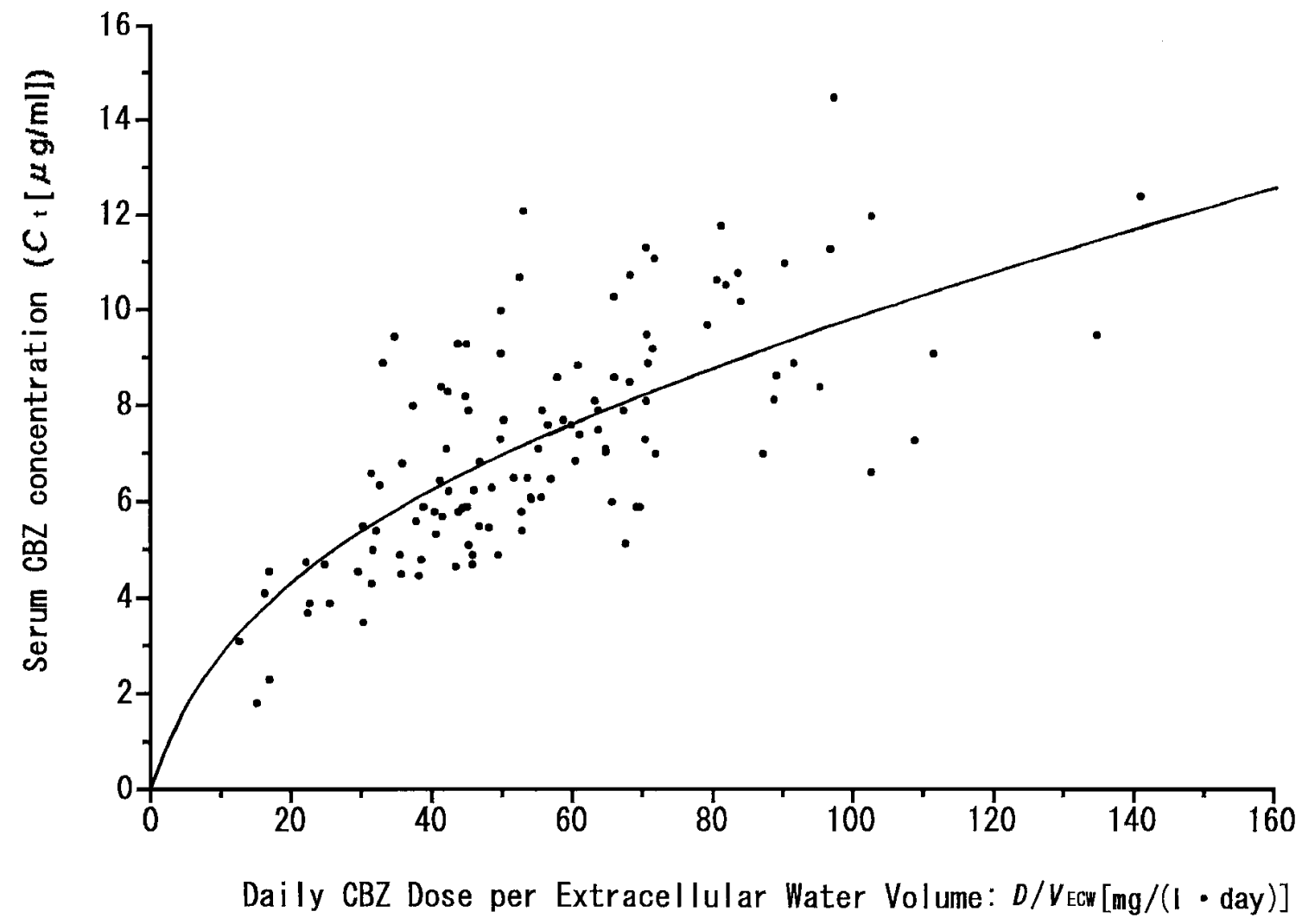

Fig. 1. Relation between the Daily CBZ Dose per Extracellular Water Volume $\left(D / V_{\mathrm{ECW}}\right)$ and the Serum CBZ Concentration $\left(C_{\mathrm{t}}\right)$ Solid curve represents the regression curve calculated from Eq. (1).

Table 2. Comparison of Regression Line of $C_{\mathrm{t}}$ for CBZ Alone with Those for Another Concomitant Antiepileptic Drug with CBZ

\begin{tabular}{|c|c|c|c|c|c|}
\hline Drug coadministered & No. of data (n) points & Regression line & $S_{\mathrm{y}}$ & Comparison of slope & $\begin{array}{c}\text { Comparison of } \\
\text { elevation }\end{array}$ \\
\hline Phenobarbital & 7 & $y=0.596 x-0.371$ & 0.208 & $\mathrm{NS}(p=0.948)$ & $p<0.001$ \\
\hline Phenytoin & 33 & $y=0.800 x-0.720$ & 0.164 & $\mathrm{NS}(p=0.069)$ & $p<0.001$ \\
\hline Valproic acid & 39 & $y=0.420 x+0.091$ & 0.102 & $\mathrm{NS}(p=0.061)$ & $\mathrm{NS}(p=0.106)$ \\
\hline Zonisamide & 10 & $y=0.504 x-0.068$ & 0.096 & $\mathrm{NS}(p=0.657)$ & $\mathrm{NS}(p=0.081)$ \\
\hline Clonazepam & 1 & - & - & - & - \\
\hline Ethosuximide & 1 & - & - & - & - \\
\hline Carbamazepine alone & 119 & $y=0.586 x-0.163$ & 0.099 & & \\
\hline
\end{tabular}

$D / V_{\mathrm{ECW}}$. We postulated the convenient Eq. (1), in which $C_{\mathrm{t}}$ is proportional to the power function of $D /$ $V_{\mathrm{ECW}}$. Using a nonlinear least-squares method, parameters $A$ and B were estimated to be 0.928 and 0.517 , respectively.

$$
C_{\mathrm{t}}=A\left(D / V_{\mathrm{ECW}}\right)^{\mathrm{B}}
$$

(2) $C_{\mathrm{t}}$ for CBZ Plus Another Antiepileptic Drug The effects of concomitant antiepileptic drugs on the $C_{\mathrm{t}}$ of CBZ were investigated. Ninety-one patients were coadministered one of six antiepileptics drug with $\mathrm{CBZ}$, i.e., phenobarbital (PB), phenytoin (PHT), VPA, zonisamide (ZNS), clonazepam (CZP), and ethosuximide (ETS) were coadministered (Table 2).

We assumed that Eq. (1) could be adapted to express $C_{\mathrm{t}}$ in the coadministration of another antiepileptic drug with CBZ. Both members of Eq. (1) were converted into common logarithms, 


$$
y=a+b x
$$

where $y=\log C_{\mathrm{t}}, x=\log \left(D / V_{\mathrm{ECW}}\right), a=\log A$, and $b$ $=\mathrm{B}$. The dose of concomitant antiepileptic drugs was not considered in this assumption. For simple regression analysis, $y$ and $x$ were assigned to be a criterion variable and an explanatory one, respectively. Then $a$ and $b$ were estimated.

Figure 2 shows the plots and regression lines of $\log$ $C_{\mathrm{t}}$ against $\log \left(D / V_{\mathrm{ECW}}\right)$ for $\mathrm{CBZ}$ alone and for the concomitant use of PB, PHT, VPA, and ZNS. The regression lines and the sample standard deviations from the regression lines $\left(S_{\mathrm{y}}\right)$ are shown in Table 2. The number of patients coadministered PRM, CZP, or ETS with CBZ was not sufficient to calculate the regression line.

A statistical method ${ }^{15)}$ was used to compare the regression line 0 for $\mathrm{CBZ}$ alone with line $\mathrm{I}(\mathrm{I}=2,3,4$, 5). The results are shown in Table 2. For the slope, no significant difference was detected between line 0 and other lines I. The slope of each line I was not different from that of line 0 , and thus all the lines may be parallel. On the other hand, for the elevation, significant differences were detected for PB and PHT, but not for VPA and ZNS. These results indicate that $C_{\mathrm{t}}$ is affected at each definite ratio by PB and PHT, but not by VPA and ZNS.

(3) Model Representing the Effects of Concomitant Antiepileptic Drugs From the results mentioned above, we postulated Eq. (3) to analyze their ratios quantitatively.

$$
C_{\mathrm{t}}=A\left(D / V_{\mathrm{ECW}}\right)^{\mathrm{B}} \cdot \prod_{\mathrm{i}=1}^{7} R_{\mathrm{i}}^{Z_{\mathrm{i}}}
$$

where $R_{\mathrm{i}}$ is a parameter representing the effect of each concomitant antiepileptic drug on $C_{\mathrm{t}}$ with $\mathrm{CBZ}$ alone,

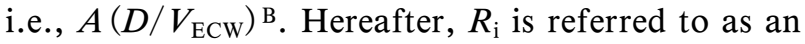
alteration ratio. The subscript $i$ represents the concomitant drug, and $i=1,2, \cdots, 7$ corresponds to primidone (PRM), PB, PHT, VPA, ZNS, CZP, and ETS, respectively. $z_{\mathrm{i}}$ is 1 or 0 when drug $i$ is coadministered or not. The doses of concomitant antiepileptic drugs were not considered in this model.

In Eq. (3), $C_{\mathrm{t}}$ is expressed under the assumption that the effects of concomitant antiepileptic drugs on $C_{\mathrm{t}}$ are independent from one another and multiplicative.

When both members of Eq. (3) are converted into

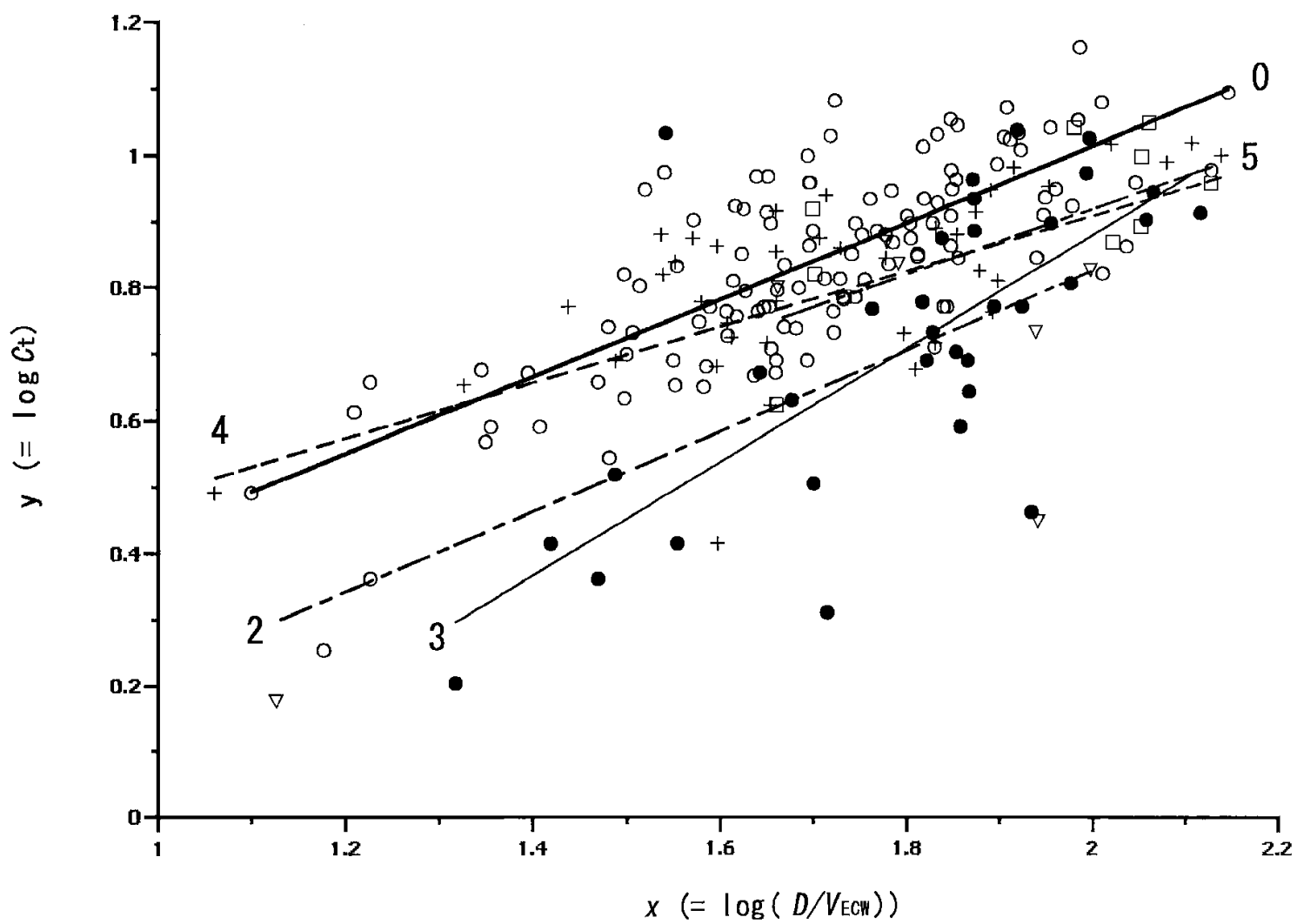

Fig. 2. Converted Plots and Regression Lines for CBZ Alone and CBZ Plus Another Antiepileptic Drug

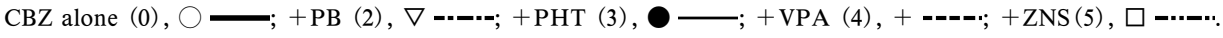


common logarithms,

$$
y=a+b x+\sum_{\mathrm{i}=1}^{7} r_{\mathrm{i}} Z_{\mathrm{i}}
$$

where $y=\log C_{\mathrm{t}}, a=\log A, b=\mathrm{B}, x=\log \left(D / V_{\mathrm{ECW}}\right)$, and $r_{\mathrm{i}}=\log R_{\mathrm{i}}$. For multiple regression analysis, $y$ and $x$ were assigned to be a criterion variable and an explanatory one, respectively. Then $a, b$, and $r_{\mathrm{i}}$ were estimated. The level of significance discriminating the addition and/or elimination of a variable using the Ftest was taken as 0.05 .

A total of 119 patients was administered CBZ alone, while $91,39,19$, and 6 patients were coadministered one, two, three, and more than four different antiepileptic drugs (Table 1). A total of 274 cases was analyzed using Eq. (4) for multiple regression analysis. The results are shown in Table 3 .

In the multiple regression analysis, the forward selection method was used to select the variables influencing $C_{\mathrm{t}}$. PB and PHT were selected as the antiepileptic drugs influencing $C_{\mathrm{t}}$ (to be more precise, they influenced $\left.y\left(=\log C_{\mathrm{t}}\right)\right)$. These drugs lower $C_{\mathrm{t}}$ to 0.770 and 0.710 the value for $\mathrm{CBZ}$ alone in concomitant use, respectively.

Multiple regression analysis with no variable selection method estimated $r_{5}$ for ZNS as -0.027 , and the value is 0.941 for $R$. The standard deviation of $r_{5}$ was 0.023 and nearly equal to those of PB, PHT, and VPA. Thus ZNS can be said to have no effect on $C_{\mathrm{t}}$. PRM, CZP, and ETS altered $C_{\mathrm{t}}$ to $0.932,0.912$, and 0.681 , respectively, compared with the value for $\mathrm{CBZ}$ alone. However, multiple regression analysis using the variable selection method did not select them as drugs influencing $C_{t}$. Because the number of the patients administered these drugs was not sufficient and the data were scattered widely, their effects on $C_{\mathrm{t}}$ were not detected.

\section{DISCUSSION}

Major determinant factors of CBZ disposition are autoinduction and concomitant therapy. ${ }^{16)}$ In our patients, autoinduction could be neglected because of the sufficiently long administration periods. ${ }^{17)}$ Numerous reports have mentioned the effects of concomitant antiepileptic drugs on $C_{\mathrm{t}}$, but no attention has been paid to the effects of confounding factors, such as age and sex. We conducted a study to clarify the effects of concomitant antiepileptic drugs on $C_{\mathrm{t}}$, without being affected by confounding factors.

When $C_{\mathrm{t}}$ is not directly proportional to $D / V_{\mathrm{ECW}}$, if the power function of $D / V_{\mathrm{ECW}}$ could be substituted for a regression curve, the curve could be converted into a straight line by taking logarithms of both members. Then the effects of concomitant antiepileptic drugs on $C_{\mathrm{t}}$ could be investigated by comparing the regression line on $\log C_{\mathrm{t}}$ vs. $\log \left(D / V_{\mathrm{ECW}}\right)$ for $\mathrm{CBZ}$ alone with that for CBZ plus another concomitant drug. Eq. (1) proposed in this paper represents the $C_{\mathrm{t}}$ $-\left(D / V_{\mathrm{ECW}}\right)$ relation fairly well (Fig. 1). Each distribution of residuals from Eq. (1) and Eq. (2) for $\mathrm{CBZ}$ alone and for $\mathrm{CBZ}+\mathrm{PHT}$ approximated a nor-

Table 3. Parameter Values Estimated by Multiple Regression Analysis

\begin{tabular}{|c|c|c|c|}
\hline \multirow{2}{*}{$\begin{array}{l}\text { Parameter, } r_{\mathrm{i}}: \text { drug } \\
\text { coadministered }\end{array}$} & \multirow{2}{*}{$\begin{array}{l}\text { No. of cases } \\
\sum_{\mathrm{j}=1}^{274} \mathrm{Z}_{\mathrm{ij}}\end{array}$} & \multicolumn{2}{|c|}{ Estimated value $\pm \mathrm{SE}$} \\
\hline & & $\begin{array}{l}\text { Variable selection } \\
\text { method }\end{array}$ & $\begin{array}{c}\text { No Variable selection } \\
\text { method }\end{array}$ \\
\hline$r_{1}: \mathrm{PRM}$ & 9 & - & $-0.030 \pm 0.045(0.932)$ \\
\hline$r_{2}: \mathrm{PB}$ & 45 & $-0.113 \pm 0.021(0.770)$ & $-0.109 \pm 0.023(0.779)$ \\
\hline$r_{3}: \mathrm{PHT}$ & 70 & $-0.149 \pm 0.018(0.710)$ & $-0.150 \pm 0.018(0.708)$ \\
\hline$r_{4}:$ VPA & 84 & - & $0.004 \pm 0.017(1.009)$ \\
\hline$r_{5}: \mathrm{ZNS}$ & 31 & - & $-0.027 \pm 0.023(0.941)$ \\
\hline$r_{6}: \mathrm{CZP}$ & 12 & - & $-0.040 \pm 0.036(0.912)$ \\
\hline$r_{7}:$ ETS & 1 & - & $-0.167 \pm 0.119(0.681)$ \\
\hline$a: \mathrm{CBZ}$ & \multirow{2}{*}{274} & $-0.119 \pm 0.060(0.760)$ & $-0.136 \pm 0.062(0.732)$ \\
\hline$b: \mathrm{CBZ}$ & & $0.552 \pm 0.035$ & $0.564+0.035$ \\
\hline \multicolumn{2}{|c|}{$\begin{array}{l}\text { Sample standard deviation from } \\
\text { regression equation, } S_{\mathrm{y}}\end{array}$} & 0.119 & 0.119 \\
\hline \multicolumn{2}{|c|}{ Multiple correlation coefficient } & 0.773 & 0.778 \\
\hline
\end{tabular}

Values in parentheses represent $R_{\mathrm{i}}\left(R_{\mathrm{i}}=10^{r_{\mathrm{i}}}\right)$ and $A\left(A=10^{\mathrm{a}}\right)$ calculated from estimated values $r_{\mathrm{i}}$ and $a$. 
mal distribution. Eq. (1) detected the effects of concomitant antiepileptic drugs on $C_{\mathrm{t}}$.

Parameters $A$ and B in Eq. (1) are closely linked with the ratio of the bioavailability to the elimination rate constant, and the curvature of the fitting curve of CBZ binding to plasma protein, ${ }^{10)}$ respectively. The effects of concomitant antiepileptic drugs result in differences in the slope or elevation in Eq. (2), respectively. The slopes of all lines did not differ, but neither of the elevations for PB and PHT were equal to that of CBZ alone (Fig. 2, Table 2). The former result agreed with the reports that PHT, VPA, ${ }^{18)}$ and ZNS ${ }^{19)}$ did not affect the plasma protein binding of CBZ. The latter result indicated that $A$ in Eq. (1) was altered by concomitant drugs. Thus $C_{\mathrm{t}}$ is affected at each definite ratio by these antiepileptic drugs. Because the bioavailability is considered to be almost constant, the change in the elimination rate would be reflected in each $R_{\mathrm{i}}$ value.

Eq. (3) was postulated for a detailed investigation of the interactions among antiepileptic drugs. The $S_{\mathrm{y}}$ value for CBZ alone in the simple regression analysis was 0.099 (Table 2), and $S_{\mathrm{y}}$ for all cases including one to more than four concomitant antiepileptic drugs was 0.119 (Table 3, using the variable selection method). Since there is little difference between both $S_{\mathrm{y}}$ values, Eq. (3) is considered useful. As this model can analyze all cases inclusively, the reliability of the estimated parameters is increased.

Multiple regression analysis revealed that $\mathrm{PB}$ and PHT lowered $C_{\mathrm{t}}$ to 0.770 and 0.710 , respectively (Table 3). Our results agreed with the reports that $\mathrm{PB}$ and PHT lowered $C_{\mathrm{t}}$ with concomitant use.2) The result that $R<1$ indicates that $\mathrm{PB}$ and PHT mainly increase the value of the elimination rate constant. These findings are due to the inducing actions of drug-metabolizing enzymes in these antiepileptic drugs. ${ }^{9,20)}$ On the contrary, VPA ${ }^{21)}$ and $\mathrm{ZNS}^{22)}$ were not reported to affect $C_{\mathrm{t}}$, in agreement with our results. Although it was not clarified whether PRM affected $C_{\mathrm{t}}$, PRM is anticipated to lower $C_{\mathrm{t}}$ due to the metabolization of PB.

When the concomitant use of PB or PHT is changed in a patient, the alteration in $C_{\mathrm{t}}$ can be estimated from Eq. (3) by using the values of $R_{2}$ and $R_{3}$ (Table 3).

When $C_{\mathrm{t}(2,3)}$ represents $C_{\mathrm{t}}$ during concomitant therapy with $\mathrm{PB}, \mathrm{PHT}$, and $\mathrm{CBZ}$ and $C_{\mathrm{t}(3)}$ represents $C_{\mathrm{t}}$ during therapy with PHT and CBZ, $C_{\mathrm{t}(2,3)}$ and $C_{\mathrm{t}(3)}$ can be written as

$$
\begin{aligned}
C_{\mathrm{t}(2,3)} & =A X_{(0)}^{\mathrm{B}} \times R_{2} \times R_{3} \\
C_{\mathrm{t}(3)} & =A X_{(0)}^{\mathrm{B}} \times R_{3}
\end{aligned}
$$

where $X_{(0)}$ is the daily CBZ dose $(D)$ per extracellular water volume $\left(V_{\mathrm{ECW}}\right)$. From Eqs. (5) and (6):

$$
\begin{aligned}
C_{\mathrm{t}(3)} & =C_{\mathrm{t}(2,3)} \times 1 / R_{2} \\
& =C_{\mathrm{t}(2,3)} \times 1 / 0.770 \\
& =C_{\mathrm{t}(2,3)} \times 1.30
\end{aligned}
$$

Thus $C_{\mathrm{t}}$ is expected to increase to 1.30 upon discontinuation of $\mathrm{PB}$.

To maintain $C_{\mathrm{t}}$, the daily CBZ dose can be estimated by setting $C_{\mathrm{t}(2,3)}=C_{\mathrm{t}(3)}$. Then

$$
A X_{(0)}^{\mathrm{B}} \times R_{2} \times R_{3}=A X_{(3)}^{\mathrm{B}} \times R_{3}
$$

where $X_{(3)}$ is $D_{(3)} / V_{\mathrm{ECW}}$ and $D(3)$ is the daily CBZ dose after discontinuation of PB. Substituting $D_{(0)} /$ $V_{\mathrm{ECW}}$ and $D_{(3)} / V_{\mathrm{ECW}}$ in $X_{(0)}$ and $X_{(3)}$, respectively, and rearranging:

$$
\begin{aligned}
D_{(3)} & =R_{2}^{(1 / \mathrm{B})} \times D_{(0)} \\
& =0.770^{(1 / 0.517)} \times D_{(0)} \\
& =0.603 \times D_{(0)}
\end{aligned}
$$

As $D_{(0)}$ is the daily CBZ dose before discontinuation of $\mathrm{PB}$, the daily $\mathrm{CBZ}$ dose after discontinuation should be decreased to 0.603 to maintain the same level of $C_{\mathrm{t}}$.

To evaluate the value of each $R_{\mathrm{i}}$ obtained in this study, the measured and estimated values of $C_{\mathrm{t}}$ were compared between the cases where the prescribed drugs were changed in the same patient. For PB and PHT, the value of each $R_{\mathrm{i}}$ was obtained by multiple regression analysis using the variable selection method (Table 3). For PRM, VPA, ZNS, CZP, and ETS, the value of each $R_{\mathrm{i}}$ was postulated to be 1 . Figure 3 shows the plots of estimated $C_{\mathrm{t}}$ versus measured $C_{\mathrm{t}}$ values. Both values appear to be in good agreement. The mean absolute error (MAE) was calculated to be $18.7 \%$ using the following equation.

$\operatorname{MAE}(\%)=\sum\{(\mid$ measured value-estimated value $\mid$

$/$ measured value) $/ \mathrm{n}\} \times 100$

(n: number of sets compared)

Each regression line for the relationship between $D$ $/ W$ and $C_{\mathrm{t}}$ for CBZ alone, CBZ + PHT, and CBZ+ PB was reported. ${ }^{9)}$ The MAE calculated in the same manner was $23.1 \%$. This value shows that better results were obtained in the present study.

Although our study was a retrospective one and our clinical data were scattered widely, we feel confident of the results. Each alteration ratio of $R_{\mathrm{i}}$ in our study population could be adapted to the patients without being grouped by other confounding factors. This 


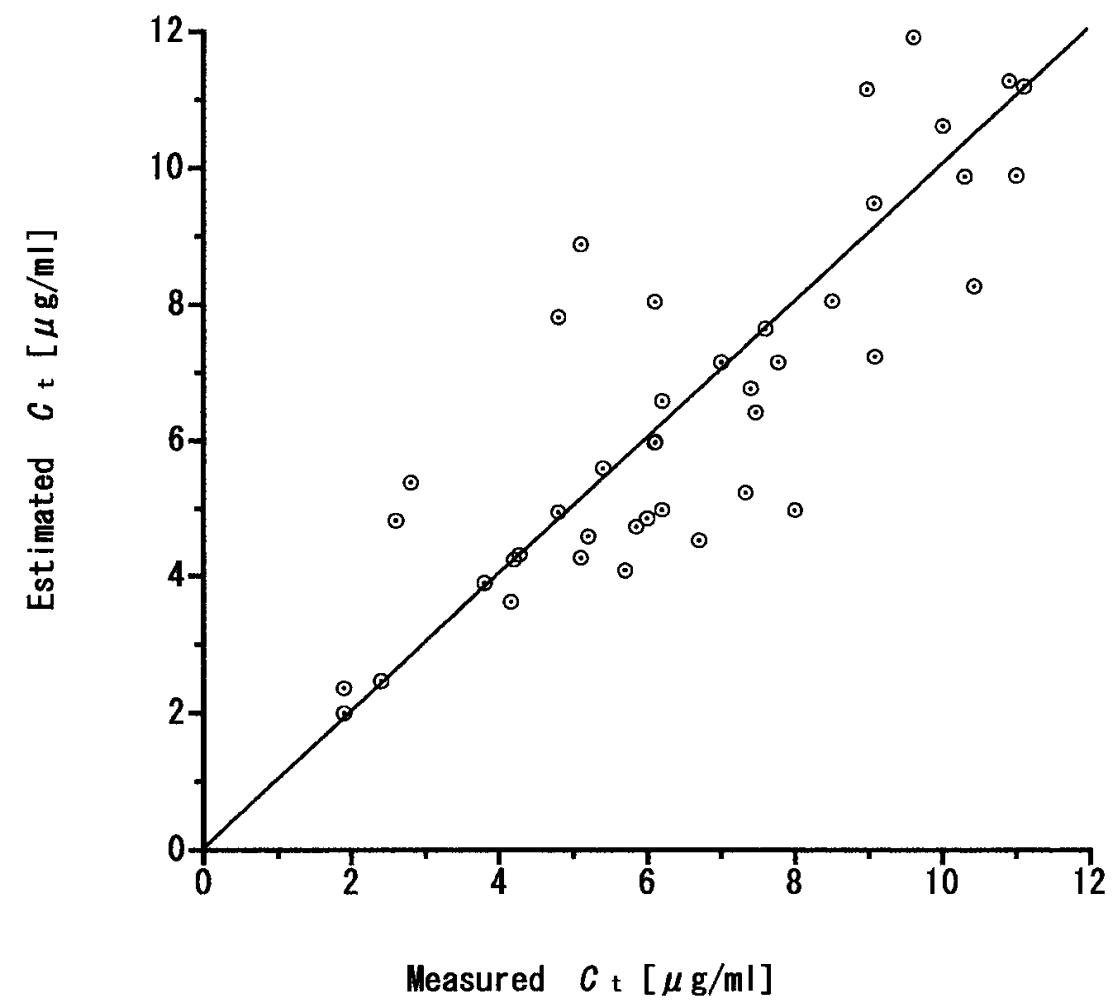

Fig. 3. Relation between the Measured and Estimated Values of $C_{\mathrm{t}}$ When the Prescribed Drugs Are Changed in the Same Patient

makes it easy to estimate $C_{\mathrm{t}}$ correctly with the addition or discontinuation of concomitant antiepileptic drugs during CBZ treatment of epileptic patients.

\section{REFERENCES}

1) Duncan J. S., Patsalos P. N., Shorvon S. D., Epilepsia, 32, 101-155 (1991).

2) Pippenger C. E., Epilepsia, 23, 81-86 (1982).

3) Ijiri Y., Ohi K., Suzuki K., Kobayashi T., Fukuoka E., Furuya T., Tamai H., Wakamiya E., Mino M., Yoshinari S., Jpn. J. Hosp. Pharm., 22, 81-88 (1996).

4) Suzuki Y., Cox S., Hayes J., Walson P. D., Ther. Drug Monit., 13, 201-208 (1991).

5) Suzuki A., Yukawa E., Ohtsubo K., Ieiri I., Teshima D., Higuchi S., Aoyama T., Jpn. J. Hosp. Pharm., 17, 26-33 (1991).

6) Kihira K., Tanaka N., Kimura Y., Miyake K., Kitaura T., Fukuchi H., Jpn. J. Hosp. Pharm., 21, 276-281 (1995).

7) Battino D., Bossi L., Croci D., Franceschetti S., Gomeni C., Moise A., Vitali A., Ther. Drug Monit., 2, 315-322 (1980).

8) Lander C. M., Eadie M. J., Tyrer J. H., Clin.
Exp. Neurol., 14, 184-193 (1977).

9) Christiansen J., Dam M., Acta Neurol. Scand., 49, 543-546 (1973) .

10) Fukuoka N., Tsukamoto T., Uno J., Kimura M., Morita S., Jpn. J. Hosp. Pharm., 26, 135144 (2000).

11) Fukuoka N., Tsukamoto T., Uno J., Kimura M., Morita S., Jpn. J. Hosp. Pharm ., 24, 642651 (1998).

12) Fukuoka N., Tsukamoto T., Uno J., Kimura M., Morita S., Jpn. J. Hosp. Pharm., 24, 652660 (1998).

13) Aoki S., "Tokei Program Package NAP (ver. 4.0) Manual," Igaku Shoin, Tokyo, 1995.

14) Friis-Hansen B., Pediatrics, 28, 169-181 (1961).

15) Snedecor G. W., Cochran W. G., "Statistical Methods, 6th edn.," translated by Hatamura M., Okuno C., Tsumura Y., Iwanami Shoten, Tokyo, 1974, pp. 405-408.

16) Bertilsson L., Hojer B., Tybring G., Osterloh J., Rane A., Clin. Pharmacol. Ther., 27, 8388 (1980).

17) Kugoh T., “Tenkangaku no Rinshou,” Seiwa 
Shoten, Tokyo, 1996, pp. 361-364.

18) Hosoya J., Nagaoka H., Ishikawa S., Nakagawa Y., Higashitani Y., Totsuka S., Jpn. J. Hosp. Pharm., 16, 277-287 (1990).

19) Kihira M., Tanaka N., Kimura Y., Miyake K., Kitaura T., Fukuchi H., Biol. Pharm. Bull., 16, 722-725 (1993).

20) Hori R., Okumura K., Kitazawa S., Koshiro A., Saitoh Y., Higuchi S., Mizugaki M.,
Yamaji A., Rikihisa T., Tanigawara Y., Yakuzaigaku, 49, 304-312 (1989).

21) Nakashima M., Ueshima Y., Hirai M., Nakashima M., Tatsuo E., Nakaboh Y., Kamimura N., Matsuzaka T., Tsuji Y., Ichikawa M., TDM Kenkyu, 13, 56-60 (1996).

22) Konishi H., Morita K., Ono T., Shimakawa H., Yakuzaigaku, 50, 323-328 (1990) . 